\title{
1. COVID-19: Assessing impacts and policy responses for food and nutrition security
}

\author{
Johan Swinnen and John McDermott
}

COVID-19 has severely disrupted our lives, jeopardized the well-being of billions of people, and raised the specter of a global food crisis, all in just a few months. The huge impact expected on the world's economy and on global food security has been described in dramatic terms. The World Bank forecasts that the global economy will shrink by more than $5 \%$, which would be the deepest recession since the Second World War. IFPRI researchers estimate that, in the absence of strong interventions in developing countries, the number of people in extreme poverty could increase by up to 150 million. The World Food Programme's executive director, David Beasley, has warned that the world is "not only facing a global health pandemic but also a global humanitarian catastrophe," and that, without action, COVID-19 could lead to "multiple famines of biblical proportions." Lawrence Haddad, executive director of GAIN, lamented that the coming food and nutrition crisis is not only biblical but "on steroids, and across generations."

Why such dire predictions? COVID-19 may not be as deadly as historical plagues or, more recently, the 1918-19 Spanish flu or Ebola, but it is unpredictable and highly transmissible, including by people who are asymptomatic but infected. This makes it difficult to control. Today's interconnected world has allowed the virus to spread with remarkable speed. On January 9, 2020, China officially recognized the first death from COVID-19, and by early March more than 100 countries were reporting cases (Figure 1). The number of officially reported cases has continued to increase, topping 10 million at the end of June. Over this period, the virus epicenter has shifted from China to Europe and the United States, and now many poor countries and regions including Africa, Latin America, and South Asia are facing rapidly rising infection rates and deaths.

More importantly, COVID-19 is a health crisis with multiple and widespread impacts on food systems, social systems, and economic development. The need to change daily practices and routines, many essential to livelihoods, and the consequent disruption of connections at local, regional, and global levels make the COVID-19 shock different from economic and climate shocks. And compared with previous pandemics, the much greater interconnection of trade and markets today - and the more complex nature of food, health, and economic systems - is amplifying the potential of COVID-19 to aggravate poverty and disrupt food systems. As a result, the impacts on well-being will be large relative to disease mortality rates.

The chapters in this book look across the broad range of impacts of this unprecedented crisis, providing forecasts, evidence, analysis, and recommendations for more effective policy responses to support food security. They draw on a combination of conceptual arguments, global and country-level simulation models, in-country surveys, case studies, and expert opinions. Key insights from the different contributions are the following. 
The virus infections and public health responses to control COVID-19 transmission have had severe economic consequences. In an effort to control the disease, governments have imposed lockdowns that have shuttered many businesses, restricted travel within countries, closed borders to human traffic and trade in some food products, and imposed social distancing requirements and curfews that disrupt economic activity and force businesses and schools to close. The result has been economic recession, with spikes in unemployment, and major disruption of food systems and supply chains, as labor, transport, and trade are impeded.

The combined impact of recession and disruption is especially detrimental for the poor, who have been acutely affected by lost or decreased incomes and remittances as the pandemic has led to a severe economic recession in many countries. Simulations predicted that the poorest groups in society would see their relative incomes fall more than wealthier social groups, and early survey results from Ethiopia confirm these predictions. Poor people, whose main asset is their physical labor, have also suffered the most from the effects of lockdowns. The case studies on China (interruption of rural-urban migration), Egypt (declining tourism), and Myanmar (interruption of international migration) confirm that the economic and poverty effects of the fall in remittances due to lockdowns and travel restrictions are huge. Disruption of some of the public programs they rely on has aggravated the differential impacts on the poor. At the same time, however, many governments have responded with the introduction of new safety net programs and expansion of existing programs that can offset some of the lost income.

Women are likely to suffer more adverse impacts from the crisis. Income shocks and lockdowns have changed household and community gender dynamics and increased the disadvantages faced by women. Because of the potential for gender bias in government policies responding to COVID-19, it is crucial that social safety net programs explicitly account for gender effects in order to mitigate negative consequences during the emergency response period.

The severe disruption of food systems - including restrictions on labor and interruption of transport, processing, retailing, and input distribution - threatens the food and nutrition security of the poor. COVID-19 has exposed fragilities in food systems, especially in labor-intensive systems, such as those for fresh fruits and vegetables. The breakdown of supply chains due to the virus infection itself and a variety of policy restrictions has caused consumer prices to increase and producer prices to fall at the same time, increasing food insecurity for both urban and rural poor. Many poor people also suffered as their employment in food supply chains - transporting, marketing, and selling food - came to a halt. A series of country simulations of the food and economic sector impacts of COVID-19 (initial results are available for China, Egypt, South Africa, Myanmar, and India) show that income declines in food services and processing have been particularly strong. Impacts on farming itself are somewhat less severe, as many small farmers rely on family labor. However, it will be important to track the extent to which constrained access to key farm inputs and distorted prices affects investments in next years' production.

Early concerns over disruptions of global supply chains focused on the introduction of several trade constraints, in particular export bans in rice and wheat markets, by major exporting countries. Such export bans and trade restrictions threatened to exacerbate global food supply problems. Several of the initially introduced export constraints have since been removed. However, many other COVID-related government restrictions are causing unnecessary problems, both for trade between 
COVID-19 cases surpass 100,000

UN Crisis Management Team warns against lifting lockdowns prematurely

Outbreaks in Western Europe stabilize, upward trends continue in Africa, Central and South America, and Eastern Europe

China lifts its lockdown on Wuhan

India begins lockdown

\section{Total confirmed COVID-19 deaths}

Limited testing and challenges in the attribution of the cause of death mean that the number of confirmed deaths may not be an accurate count of the true number of deaths from COVID-19. 
developing countries and food marketing inside developing countries. In some countries, blanket policy actions, such as market and trade restrictions and curfews, are impeding food supply chains, while other countries were able to avoid these disruptions.

COVID-19 disruptions have also had negative consequences for long-term and hard-won progress on nutrition. Disruption of livelihoods and food supply chains means diets have become less healthy and nutrition programming for the poor and vulnerable has been interrupted. A simulation points to significant global declines in more nutritious but more expensive products such as fruits and vegetables and dairy products. Early survey results from Ethiopia on the vegetable and dairy supply chains confirm these simulation and expert predictions. Consumption of healthy diet ingredients has declined, and has declined most for the poorest groups in society. However, nutrition experts point to some viable options for mitigating negative nutrition consequences and for actions to hasten recovery and a return to the long-term positive trajectory of the past decade.

There are also other positive signs. While many food systems have been significantly disrupted, others have been more resilient, with food supplies relatively unaffected. Government responses to the crisis have varied widely, and some responses have had more positive effects than others. Innovation is occurring in many social programs and in NGO activities to overcome the constraints created by government regulations and health programs. Likewise, innovations and entrepreneurship in private food supply chains are helping to overcome obstacles and make food supply chains more resilient for the future. One example is the use of information and communications technology and e-commerce, which is growing at a much faster pace than expected prior to the COVID-19 outbreak. The country studies also predict significant economic rebounds in several countries once the lockdown measures are removed.

Looking forward, an intriguing question is about the next pandemics. In the recent past, epidemic/ pandemic diseases have mainly emerged from Asia, but in the future disease emergence is likely to become more common and more disruptive in Africa as population densities, natural resource exploitation, and economic and social integration increase dramatically. The lessons we learn from COVID-19 should help us to design better policies and to build more resilient and inclusive food systems that limit the impact of future pandemics.

This collection of short essays provides a fairly comprehensive overview of where we are and what we know about how COVID-19 is affecting food security and livelihoods at the six-month mark. More specifically, they provide a detailed look at policy responses across the globe and how effectively they are working, along with recommendations for further innovations. In the coming months, new survey data, model simulations for more countries, and better insights on the spread of the virus, policy impacts, and innovations in public and private components of food systems will no doubt enhance our understanding. The IFPRI COVID-19 blog series will continue to report on new insights and on emerging issues, such as country policy responses and balancing their effects on health and economies; investments in short- and long-term responses to COVID-19 and their effects; reshaping food trade and supply chains in the recovery phase to manage continuing COVID risks; and evolving impacts on poor and vulnerable populations and how these can be monitored and mitigated. 